\title{
Critical Perspective to Genre Analysis: Intertextuality and Interdiscursivity in Electronic Mail Communication
}

\author{
Mohammad Awad AlAfnan \\ Liberal Arts Department, American University of the Middle East, Eqilah, Kuwait \\ Email: mohammad.al-afnan@aum.edu.kw
}

How to cite this paper: AlAfnan, M. A. (2017). Critical Perspective to Genre Analysis: Intertextuality and Interdiscursivity in Electronic Mail Communication. Advances in Journalism and Communication, 5, 2349.

https://doi.org/10.4236/ajc.2017.51002

Received: October 14, 2016

Accepted: March 4, 2017

Published: March 7, 2017

Copyright $\odot 2017$ by author and Scientific Research Publishing Inc. This work is licensed under the Creative Commons Attribution International License (CC BY 4.0). http://creativecommons.org/licenses/by/4.0/

\begin{abstract}
This study examined intertextuality and interdiscursivity in email exchanges in an Institute in Malaysia. Intertextuality observed how and why the discourse community repeatedly used certain forms to respond to reoccurring rhetorical situations and how they used their professional knowledge to identify the authority of certain texts on other text. Interdiscursivity examined how and why the employees of the Institute appropriated the generic resources of a genre to create another. This study found that the discourse community skillfully used three types of intertextuality to achieve similar and contradicting communicative purposes. They also appropriated generic resources of a genre to create another.
\end{abstract}

\section{Keywords}

Critical Genre Analysis, Email Communication, Intertextuality, Interdiscursivity, Hybrid Genres

\section{Introduction: Critical Perspective to Genre Analysis}

The critical enquiry in language studies, according to Wodak (2006), could be traced back to the work of Pecheux (1982), who adopted the work of Bakhtin (1981). The term "critical", here, intends to not only "describe and explain" the linguistic features of texts, but additionally, to "root out any particular kind of delusion" (Wodak, 2006: p. 3). Researchers applied the term "Critical Linguistics" (CL) (Fowler et al., 1979; Kress \& Hodge, 1979) to investigate the relationships between the linguistic structures of texts and link them to the broader social structures. Simpson (1993) noted that "critical linguistics like stylistics, seeks to interpret texts on the basis of linguistic analysis", and that critical linguistics "expands the horizons of stylistics by focusing on texts other than those regarded 
as literary" (p. 5). Simpson also noticed that while the inspiration of stylistics is observing the rhetorical and the metaphorical aspects of the text, critical linguistics is more into the political and the historical dimension and directed to change not only observe reality.

Building on CL, Fairclough (1989, p. 5) presented his "Critical Language Study", which is widely known as critical discourse analysis (CDA). For Fairclough (1993), critical discourse analysis aims at investigating the relationship between discourse practices and the wider social and cultural context. It also investigates how textual practices reflect power relations. Critical discourse analysis then is not a simple discipline or narrowly defined theory; it is "not a homogeneous method, nor school or a paradigm, but at most a shared perspective on doing linguistic, semiotic or discourse analysis" (Van Dijk, 1993: p. 131). In analysing any communicative event, Fairclough drew attention to three main analytical nuclei, which are: the text, discourse and social practices. Text practices, according to Fairclough (1992), refer to the production of the texts. That is, text practices refer to the linguistic choice of words in the texts, which include the vocabulary and grammar. In examining the vocabulary, the focus is on the word level, whereas in examining the grammar, the focus is drawn to the sentence, clause or phrase levels (Fairclough, 1992). Discourse practices refer to the interpretation of the texts. That is how the text is produced and how it is received. In other words, as the communication cycle includes a writer or a speaker, a channel of communication and a recipient, the production of the linguistic choices depends on writers' knowledge about the world, and the interpretation of these choices depends on recipients' knowledge. As such, examining discourse practices include examining the features used and their interpretation according to the context. Social practices, however, refer to the practices that are usually used in a given context. These practices are socially and culturally constructed and used conventionally by the members of the discourse community.

Recently, the critical perspective on language studies has been prolonged to investigate genres (Bhatia, 2010a, 2010b, 2012). Genres initially were viewed as reoccurring patterns; nowadays, however, the investigation was extended to include the critical perspective that does not only include the texts, but also the institutional practices, the disciplinary conventions of the institution including the patterns of intertextuality and interdiscursivity. According to Bhatia (2012), critical discourse analysis intends to analyse the social structures and social relations including power, ideology and class relations in a way that are viewed as invulnerable. Critical genre analysis, however, intends to examine the generic artifacts to find out what is explicitly and implicitly said in the genre that reflects the private intentions of the expert members of the discourse community. Therefore, the "organizational practices are not assumed but negotiated" (Bhatia, 2012: p. 23) as they reflect competing interests. To investigate these interests, researchers need to investigate "two kinds of relationships involving texts and contexts" (Bhatia, 2010a: p. 391) that are intertextuality and interdiscursivity. 
This study adopts this critical perspective to genre analysis. It does not only investigate the textual artifacts of the text genre, but also examines the contextual and the intertextual aspects of generic integrity. This includes the influences of the institutional practices and the disciplinary conventions in the institute on the nature and the construction of the genre. This study, as such, is a descriptive and interpretive study that examines how the email genre is constructed and how it is exploited by the expert members of the discourse community. To conduct the analysis, this study examines the relationships between texts (intertextuality), the interactions between genres (interdiscursivity).

\section{Literature Review}

\subsection{Email Communication}

Previous research found that email may belong to a single or a number of genres (Kankaanranta, 2005; Orlikowski \& Yates, 1994; Yates \& Orlikowski, 1992). Kankaanranta (2005), for example, "recognized the possibility of defining genres at different levels of abstractions" (p. 58). Kankaanranta, who examined 282 emails in multinational company, asserted that, when considering the genre of email as a single genre, the investigation is on the general level that is comparable to the genre of letters and faxes. However, when the corpus-based analysis is combined with the views of the expert members of the discourse community performed "on a more concrete level to identify the communicative purposes, the action effected by the messages, and their discourse features, it was not difficult to identify the three email genres used in the company" (Kankaanranta, p. 412).

AlAfnan (2015a), who examined the communicative purposes (Swales, 1990) of email communication in an educational institute, found that the corpus of emails belong to four types of genres. Discussion genre is used to elaborate on an issue. Enquiry genre is used to request and respond to requests. Delivery email genre is used send files or scanned documents and informing email genre is used to notify recipients about general interest issues. He also noticed that the institutional practices of place discourse community influenced the construction of the genre and language use (AlAfnan, 2014a, 2015b, 2015c, 2016). AlAfnan (2014b, 2014c) also noticed that ethnicity, power relations and social distance influence the construction of the email messages. AlAfnan (2016) concluded that email genre invaded the generic integrity of other genres in the institute.

The corpus of email messages, in this study will be investigated in relation to these four types of email genres. The emails that intend to discuss an issue are considered discussion email genre messages. The emails that intend to request or respond to requests are considered enquiry email genre messages. The emails that intend to notify the recipients about a general interest issue are considered informing email genre messages. The emails that intend to deliver a document are considered delivery email genre messages.

\subsection{Intertextuality and Interdiscursivity}

Intertextuality and interdiscursivity could be traced back to the work of Kristeva 
(1980). According to Kristeva (1980), writers do not invent texts, they, nevertheless, compile them together. She called this practice intertextuality. In this regard, intertextuality in a given text is "several utterances, taken from other texts, intersect and naturalize one another" (p. 36). As such, intertextuality is the "transforming of the past [texts] into the present" (Bhatia, 2010, p. 392). Throughout the years, researchers viewed and examined intertextuality in several ways. For Fairclough (1992), intertextuality could be distinguished into manifest intertextuality and constitutive intertextuality. Manifest intertextuality refers to the presence of other specific texts in a new text; quotation marks could mark these. Constitutive intertextuality, however, refers to the conventions and the structure that go into new to new text production. The latter type is referred to as interdiscursivity. In addition, intertextuality could be divided into horizontal intertextuality and vertical intertextuality (Kristeva, 1986). Horizontal intertextuality refers to the interrelationship between a given text and other texts that proceeded or followed it, whereas vertical intertextuality refers to the relationship between a given text and other texts that constitute its more-or-less immediate or distant context.

Devitt (1991) also divided intertextuality into three different kinds that are referential, functional and generic intertextuality. Referential intertextuality, according to Devitt (1991), refers to the "reference in one text to other texts" (p. 342). Generic intertextuality refers to the repeated rhetorical forms in reoccurring rhetorical situations (Devitt, 1991). Functional intertextuality, however, refers to the "community consequences of intertextuality" (Devitt, 1991: p. 350). That is, as members of a given community in practice share professional knowledge and use a set of genres to achieve their goals, they create a form of functional intertextuality. This occur as they may "cut" from a text and "paste" in another, and that past text may impact future texts by creating the need for these future texts (Devitt, 1991). Devitt (1991), who is a new rhetorical scholar, applied these kinds of intertextuality to examine the genre in a tax accounting community. She found that the community included previous texts in a new text (referential intertextuality), repeatedly used certain forms to respond to reoccurring situations (generic intertextuality) and used the "cut-paste" technique to create a letter from a memorandum (functional intertextuality).

Interdiscursivity, however, refers to the "constitution of a text from diverse discourses and genres" (Fairclough, 1993: p. 138), it extends intertextuality "in the direction of the principle of the primacy of the order of discourse" (p. 85). The orders of discourse, according to Fairclough (2003) are not merely the elements of the linguistic structures such as the nouns and the sentences, they are the "social organization, control of linguistic variations and their elements" (p. 24). In this regard, the investigation of interdiscursivity includes linguistic, semiotic and context analysis.

In conducting linguistic analysis, Fairclough made use of Halliday's (1985) systemic functional linguistic that examines language and "other elements and aspects of social life" (Fairclough, 2003: p. 5). This included the vocabulary and 
grammar. In examining the vocabulary, the focus is on the word level, whereas in examining the grammar, the focus is drawn to the sentence, clause or phrase levels (Fairclough, 1992). Fairclough's interdiscursive analysis also incorporated semiotic and context analysis into the analysis of texts to reflect on the innovation and change in texts and to allow connecting the linguistic and the semiotic analysis to the broader social change (Fairclough, 2005).

Interdiscursivity for Fairclough (1992) is more than a stylistic phenomenon. It is a representation of social practices that occur as a result of social change. This social change, according to Fairclough (1992), occurs as a result of the democratization of discourse, commodification or marketization of discourse and technologization of discourse. In examining the discourse of higher education, Fairclough (1993) noticed interdiscursivity or mix not only on the discourse level, but also on the genre and style levels. This interdiscursivity occurred as a result of mixing the discourse of education with the discourse of the market. This mix, according to Fairclough (1993), occurred as a result of the marketization of higher education.

According to Bhatia (2010a), interdiscursivity refers to the interactions within or across genres. The investigation of interdiscursivity as a text-external aspect of generic integrity has taken a prominence role in Bhatia's $(2004,2008,2010 \mathrm{a})$ critical genre analysis. The investigation of interdiscursivity, according to Bhatia (2010a), is central to understanding professional practice. This is particularly important as the "expert members" of discourse communities communicate private intentions in socially recognized communicative purposes, which leads to creating hybrid or embedded genres. Stemming from this view, Bhatia (2010a) defined interdiscursivity as an innovative attempt to create hybrid or embedded genres by appropriating the generic resources of a genre or a practice to create another. This appropriation may occur in professional practices, by mixing the "generic norms in professional contexts" or semiotic resources such as "textual, semantic, socio-pragmatic, generic, and professional" resources (Bhatia, 2010a: p. 393).

According to Bhatia (2008), interdiscursivity, or the appropriation of generic resources, may occur between two different genres, professional practices or cultures. To examine hybrid genres, Bhatia (2010a) examined a number of annual reports that were taken from companies in Hong Kong. He found that annual reports included two different discourses that are the accounting discourse and public relations discourse. Bhatia concluded that even though these two discourses have different purposes, different corporate practices, and different textual resources and rhetorical strategies, they were placed in a single genre to reflect a good impression about the performance of the company (Bhatia, 2010a). In relation to professional practices, Bhatia (2008) exposed instances of interdiscursivity through the use of language and discourse between arbitration and litigation practices in legal discourse. In relation to professional cultures, Bhatia (2010a) found instances of interdiscursivity by appropriating semiotic resources between fundraising practices and commercial advertising. These in- 
stances of interdiscursivity, according to Bhatia (2010a, p. 399), reflect the tension between "generic integrity", on the one hand, and "appropriating the generic resources" on the other.

According to Bhatia (2010a), the term interdiscursivity is not "fully explored" (p. 392), especially in regard to the complexities in discursive and professional practices. Thus, to investigate interdiscursivity, researchers need to investigate a number of "discourses, actions and voices" that play a prominent role in the development of "specific discursive practices" within "institutional frameworks" (p. 393). In this context, interdiscursivity plays a more significant role than intertextuality, especially in professional discourse, as it examines the construction and interpretation of the text-external resources at different genres, professional practices and professional cultures (Bhatia, 2010a).

Several researchers examined intertextuality and interdiscursivity in professional discourse. As mentioned earlier, Devitt (1991) examined the genre in a tax accounting community. She identified thirteen genres including proposal, review, nontechnical correspondence and a number of memorandum and letter genres that were used for different rhetorical situations. Akar and LouhialaSalminen (1999) referred to Fairclough's concept of intertextuality in scrutinizing business fax genres. They found that the fax correspondence referred to other communicational events like phone conversations or previous faxes. Intertextuality was also apparent in the conventional method of responding to other faxes. Akar and Louhiala-Salminen found that communicators usually fax back the same fax adding their comments on it. Regarding constitutive intertextuality, Akar and Louhiala-Salminen (1999) found that fax communicators share spoken features in their faxes like having the chance for instant feedback, and involving background or presupposed knowledge.

In relation to interdiscursivity, Musson and Cohen (1996), for example, examined medical discourse in the UK. They observed aspects of interdiscursivity between the medical discourse and enterprise discourse. This interdiscursivity, according to Musson and Cohen (1996), is a product of transition in policies from state-controlled medicine to privately controlled medical practices. In another study, Sarangi (2000) examined interdiscursivity between different discourse types. He stated that genetic counselling is a discourse that includes three different moments that are giving information, seeking advice and decision-making. These three moments are different discourse types. However, he perceived that counsellors appropriate the resources of a discourse upon which to create another. In addition, Bhatia (2008, 2010a), as presented earlier in this section, provided insights into the occurrence of interdiscursivity between different genres, professional practices and disciplinary cultures. Even though the genres serve socially recognized communicative purposes (Bhatia, 1993, 1995), the expert members of the discourse community still may exploit private intentions (Bhatia, 2002) to create hybrid or mixed genres (Bhatia, 2008).

The investigation of interdiscursivity, in this study, targets the appropriation of generic resources of an email genre to create another, on the one hand, and 
using hybrid forms and styles, on the other. In regards to intertextuality, this study will examine the interrelationship within and across texts as an internal reference, functional practice and generic category that is based on repeated forms in repeated situations.

\section{The Corpus of Emails}

The corpus of emails was collected from a private higher educational institute in Malaysia. Educational institutes in Malaysia have international reputation and their ranking is getting higher year after year. They are institutions that conduct business as all other organizations and their focus is education. After receiving the consent of the chairman, I started my participant observation, which, nevertheless, helped me in identifying an information-rich expert member of the place discourse community. She became my first official informant.

Using the snowball random sampling technique, I asked the informant to suggest other expert members who use email to conduct daily business. The first informant advised me to approach the assistant academic director and few other lecturers and staff members. I took her advice and approached the staff members. To keep the ball rolling, I asked them to suggest other members and they did. Finally, I had seven expert information rich respondents who started sending me emails on day-in-day-out basses.

In the collection period, I managed to collect 522 email messages. As the analysis in this study examines language use as an institutional practice, I only included the emails that were written by the seven main informants (378). The emails that were written by other employees, external contacts and students (144 email messages) were not examined. These 144 email messages, however, were not deleted as they provided the immediate context of the email communications.

The Chairman of the Institute and the informants signed the consent form. For ethical purposes, however, the name of the Institute, the names of the informants and the respondents were replaced by pseudonyms. None of their real names appear in this article.

\section{Methods of Analysis}

This study examines intertextuality and interdiscursivity in email communication in an educational institute. The genre of email communication in educational institutions was extensively analysed in a number of recent studies (i.e. AlAfnan, 2014a, 2014b, 2015a, 2015b, 2015c, 2016). According to AlAfnan (2015a) genre of email is an umbrella for four types of genre. Discussion email genre was used to debate or negotiate an issue over a number of email messages. Register variation in this type of genre mainly included "involved" production, "narrative and non-narrative" discourse, "situation-dependent reference", "online informational" elaboration and "overt expression of argumentation" (AlAfnan, 2015a). Enquiry email genre was used for requesting and responding to request. Register variation in this type of email genre reflected "involved" production, "narrative and non-narrative" discourse, "overt expression of argumenta- 
tion" and "situation-dependent" reference (AlAfnan, 2015a). The delivery email genre, however, was used mainly to supply a document or file.Register variation in this type of email genre reflected "informational" production and "non-narrative" discourse (AlAfnan, 2015a). The informing email genre, however, was used mainly to update, notify or advise the recipients about general interest issues. Register variations of this type of email genre included the use of "abstract" style, "informational" production, and "narrative" discourse (AlAfnan, 2015a). Email genre in this study is examined based on these four types of email genre.

As mentioned earlier, the investigation of the patterns of intertextuality and interdiscursivity examine the interrelationships among or across texts and the interactions among or across genres (Bhatia, 2010a). I investigated the presence of a text in another text (referential intertextuality), the influence of texts on other texts by creating the need for these new texts (functional intertextuality) and the reoccurrence of rhetorical forms in reoccurring rhetorical situations (generic intertextuality) (Devitt, 1991).

The investigation of the patterns of interdiscursivity was carried out by examining the interactions between genres and styles (Bhatia, 2010a). In relation to "hybrid genres", the researcher investigated the appropriation of generic resources of a genre to create another (Bhatia, 2010a). This included the appropriation of the semiotic resources, which included textual and generic resources (Bhatia, 2010a, p. 393). The investigation of "hybrid style", however, included examining the mixing of written and spoken styles including non-verbal cues in the email genre messages.

\section{Email Genre}

Investigation the communicative purposes of the email messages revealed that the emails belonged to the four types of email genres identified by AlAfnan (2015a). It was found that 136 email messages intended to "discuss issues", 125 email messages intended to "request-respond to request", 64 emails "indicated enclosure" and 53 email messages intended to "inform about issues" (see the Figure 1).

The overall communicative purpose of these patterns was identified by drawing on the communicative intention of writing the email in its context. As long as the emails maintained the same communicative purpose (Bhatia, 1993, 2004; Swales, 1990) and topic (Yates \& Orlikowski, 1992), they were considered a single genre, however, when the communicative purpose or intention changed, the emails were identified as another genre (Hasan, 1977).

\section{Patterns of Intertextuality}

Intertextuality is "the way in which the texts are related to other texts" (Johnstone, 2008: p. 275). For Devitt (1991), intertextuality could be divided into generic intertextuality, referential intertextuality and functional intertextuality (Devitt, 1991). Generic intertextuality is the repeating of forms of a genre in reoccurring rhetorical situations (Devitt, 1991). Referential intertextuality refers to 


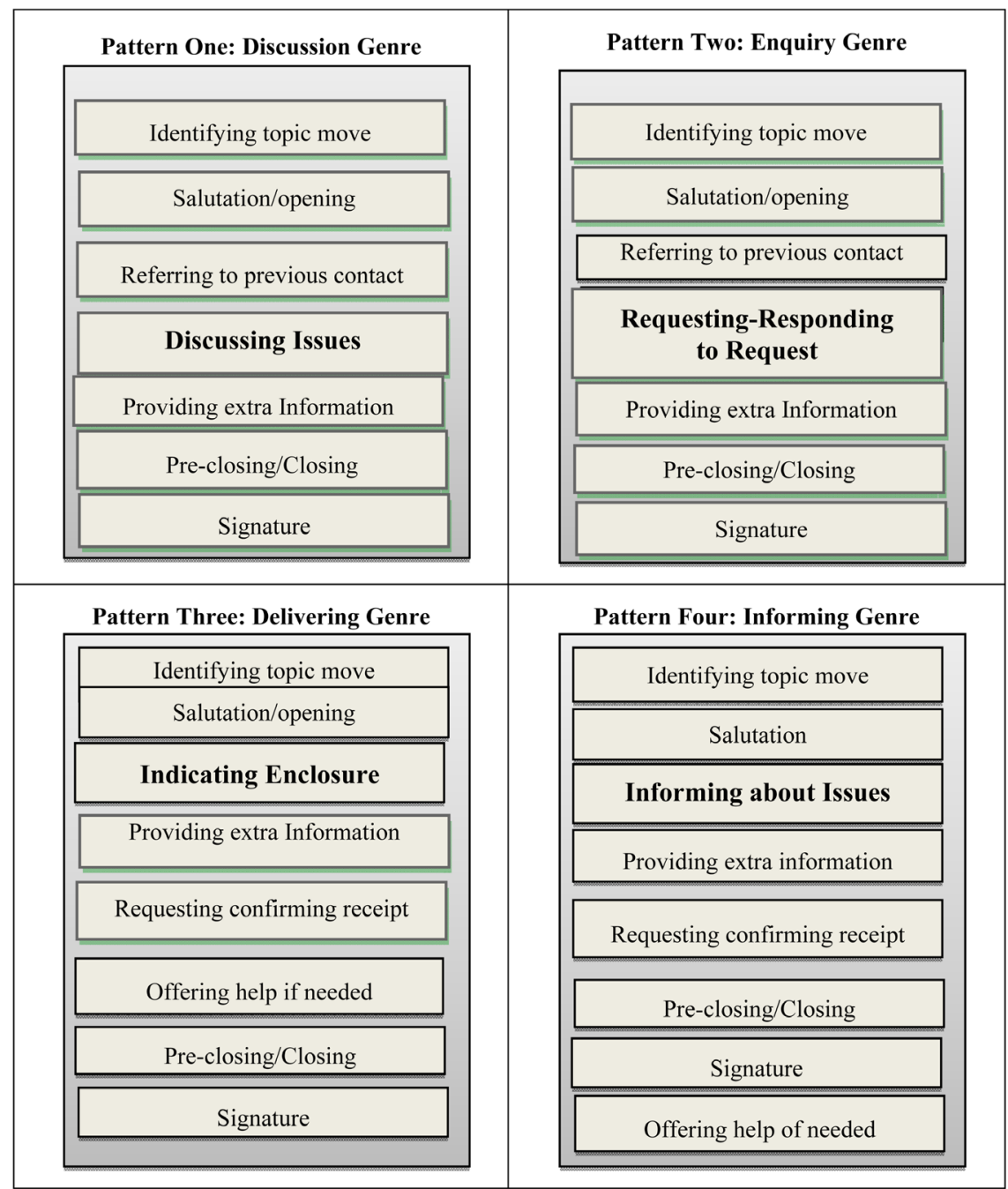

Figure 1. Generic structures in the corpus of emails.

the presence of other specific texts in the given text (Devitt, 1991). Functional intertextuality refers to the "community consequences of intertextuality" (Devitt, 1991: p. 350). That is, functional intertextuality refers to the process of using a text or part of text to create another text. Intertextuality, in this study, is examined in relation to the three different kinds of intertextuality that Devitt (1991) proposed.

\subsection{Referential Intertextuality}

Referential intertextuality was present in the email messages in three different forms that are the referring to a previous communication, referring to an attached file and referring to texts or documents. Examining the first practice of referential intertextuality in the institute shows that the expert members of the discourse community refereed to previous email messages, telephone calls, business letters, faxes, meetings and discussions. The data showed that 11 instances ( 24 percent) referred to telephone calls, 8 instances (18 percent) referred to meetings or face-to-face discussions, 2 instances (4 percent) referred to faxes, 
2 instances (4 percent) referred to business letters and 22 instances ( 49 percent) referred to previous email messages. This reflects the prominence of computer-mediated and oral methods of communications in the Institute.

The "internal reference" to previous texts in a new text reflects the relationship between texts in the educational institution. The employees of the educational institution used these different methods of communication collectively or selectively to accomplish their institutional tasks and professional activities. A telephone call or a face-to-face conversation or meeting, for example, may lead to writing an email message to discuss the issue further. A letter from the Ministry of Higher Education may also lead to writing an email message to further discuss or clarify the issues. The internal reference to previous texts in new texts intended to relate the texts into their immediate context, which assists the discourse community to "accomplish their work" (Devitt, 1991).

It was also found that referential intertextuality, in some emails, functioned as the main task of the email message as it "references to enclosed documents" (Devitt, 1991: p. 343). The writers mainly used the linguistic construct "please find attached" or "enclosed please find" to direct the attention of the addressee to the attached document or file. This type of referential intertextuality, or what Johnstone (2008) called "horizontal intertextuality", is used to refer to intertexts (Chin, 2011). It is called horizontal intertextuality as email writers would attach a file or a number of documents to the email message and use this construct to refer to them.

Referential intertextuality also occurred as a method of recalling previous texts. The writers mainly used "in accordance with the..." to refer to the rules and regulations of the institution, in general, or a certain policy, in particular, as in "in accordance with our exemption policy...". This adverbial construct was followed mainly by a notification or instruction directed to the addressee. The reference to the rules and regulations, in this sense, helped placing the text in its context, on the one hand, and acted as a negative politeness strategy to minimize imposition by stating it as a general rule, on the other (Brown \& Levinson, 1987).

\subsection{Functional Intertextuality}

Functional intertextuality, according to Devitt (1991), may occur in different ways that are using the "cut" from a text and "paste" in another and the impact of past texts on future texts by forming the necessity for those forthcoming texts. The members of the discourse community may use these techniques to create functional intertextuality as they share the "professional knowledge" in the field and use "a set of genres" (Devitt, 1991: p. 351) to achieve their goals and communicative purposes. Even though functional intertextuality was not a very common practice in the email messages, instances of the three different techniques were recorded.

The "cut-paste" technique was mainly used in the emails that were sent to a group of recipients informing them about a general rule. The expert members of the discourse community included whole segments from the rules and regula- 
tions to enlighten the employees and the students about certain issues. According to Jones and Freeman (2003), the "cut-paste" functional intertextuality technique may occur on the segment level by providing complete sentences into a new correspondence.

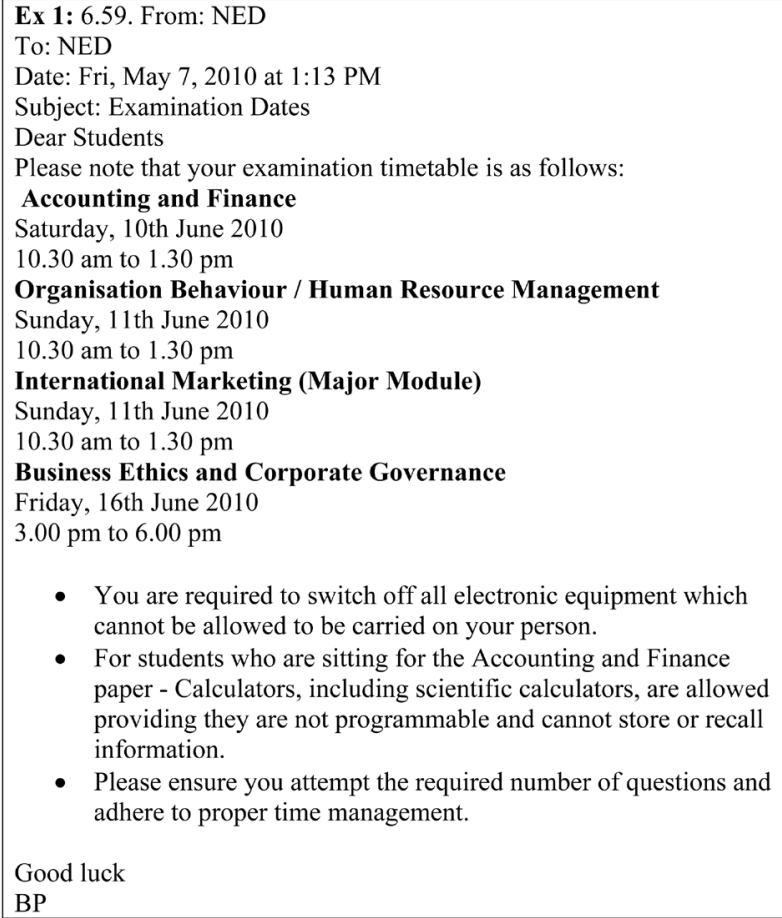

- You are required to switch off all electronic equipment which cannot be allowed to be carried on your person.

- For students who are sitting for the Accounting and Finance paper - Calculators, including scientific calculators, are allowed providing they are not programmable and cannot store or recall information.

- Please ensure you attempt the required number of questions and adhere to proper time management.

In example (1) above, the head of studies sent this email message to the students to give them the examination timetable. As the head of studies has the "professional knowledge" (Devitt, 1991) in the field and is aware of the practices that may take place in the examination hall, she chose to "cut-paste" the rules and regulations of examinations in the institution in the body of the email. Exams rules and regulations are stated in "students" handbook that is usually handed out to the students in their orientation session. They are also printed on the cover page of every single exam paper. Therefore, the head of studies, ideally, does not need to "cut-paste" the rules and regulations in the body of the email. Practically, however, as she knows the practices in examination halls, she chose to make the direct reference by using the "cut-paste" strategy, as a preliminary reminder.

The members of the discourse community also used this technique to inform or possibly remind recipients about the assignment extension policy and the rules and regulations for obtaining a full accreditation for a program. In addition to informing and reminding recipients, this strategy was also used to impersonalise the imposition of the face threatening acts that were carried out in the email messages. That is, in using the direct reference to the rules and regulations, email writers minimize or abolish the role of the agent in applying these rules. This is reflected in the excessive use of agentless passive voice in the statements (i.e., "you are required", "cannot be allowed"). 
Functional intertextuality in the email messages also occurred in the influence of previous texts on upcoming texts by generating the need for these upcoming texts. Devitt (1991), who investigated intertextuality in accounting firms, noticed that every written text is prompted by another text; however, this trace is hard to follow. The influence of past texts on creating future texts in the email messages, however, was marked by the electronically generated " $R E$ " and " $F W$ " initials in front of the subject of the replied or forwarded email messages. This type of intertextuality appeared to be common as it occurred in 45 percent of the email messages that were exchanged to discuss an issue or request document, information or action. Requesting emails were preceded by response emails, and response emails might be preceded by thanking emails. Additionally, clarification (discussion) emails were preceded by suggestion emails, and suggestion emails were preceded by another suggestion or opinion emails. This practice, as mentioned earlier, created threads or chains of intertextual email messages.

In addition to this explicit functional intertextuality, some email messages created the need for other emails that were not part of the chain or of the thread. Some email messages created the need for other emails. The "cycle of [email] texts" (Devitt, 1991: p. 252) in this type of functional intertextuality was not explicit as it took complex forms and was hard to follow (Devitt, 1991). However, as the corpus of emails was collected from day-in-day-out email communications for 45 days, it was possible to identify how certain texts created the need for other texts. The data showed that a chain of discussion or enquiry email genre messages may lead to writing an informing email genre message (AlAfnan, 2015a), a delivery email genre message may lead to a requesting email message and an informing email genre message may lead to a requesting email genre message. These intertextual emails were addressed to other recipients and had different functions.

\begin{tabular}{|l|l|}
\hline Ex 2: 3.42. From: "MAL & Ex 3: 3.56. From: BP \\
To: Bp & To: MAL \\
Sent: Sunday, 16 May, 2010 & Sent: Monday, 17May, 2010 \\
10:11:33 AM & 5:48:23 PM \\
Subject: Business Ethics & Subject: RE: Business Ethics \\
Dear BP, & Dear MAL, \\
Will it be possible for me to have an & \\
extra class (3 or 4 hours) to make up & OK, no problem. \\
for the first class that the students & Friday 4th of June from 2-5 is fine. \\
had with Mr. VA. Although Mr. VA & \\
did an introduction on ethics with & Regards, \\
them, I had to start all over when I & BP \\
took over to keep the flow of my & \\
lessons. I may give the extra class on & \\
the 4th of June from 2 to 5 pm . & \\
Cheers! MAL & \\
\hline Ex 4: 3.59. From: MAL & Ex 5: 3.79. From: BP \\
To: BP & To: STS \\
Sent: Tuesday, 18 May, 2010 & Sent: Wednesday, 19 May, 2010 \\
10:38:17 AM & 3:45:09 PM \\
Subject: RE: Business Ethics & Subject: Business Ethics Extra \\
& Class \\
Dear BP & Dear Students, \\
& Please note that Ms. MAL will \\
Thank you, I will tell the students & conduct an extra class. Your class is \\
next class. & scheduled as follows \\
MAL & Date: 4th June 2010 (Friday) \\
& Time: 2 pm - 5 pm \\
& Kind regards \\
& BP \\
\hline
\end{tabular}


In example (2) above, the writer, who is a part-time lecturer, wrote a requesting email to the head of studies. She wants to give an extra class for the students. In reply, Ms. BP, in example (3), approved the request and confirmed the time and the date of the extra class. In example (4), the lecturer thanked the head of studies and confirmed that she will inform the students in class. This chain of email messages (from example 2 - example 4) was a typical chain of enquiry email genre message. In example (5), however, the head of studies wrote an informing email genre message to the students to notify them officially about the extra class. Even though this informing email genre message seems typical, however, its cycle is traced back to the chain of the enquiry email genre messages communicated earlier. That is, there is functional intertextuality between the chain of enquiry email genre messages and the informing email genre message as the content of the chain has created the need for the informing email. Even though the lecturer stated that she will inform the students in class, which implies that she will use the face-to-face oral method, the head of studies wrote the informing message to formally notify the students about the extra class.

This type of intertextuality occurred in several forms. In addition to the example above, chains of discussion email genre messages regarding issues, such as extensions on submitting assignments, produced informing genre messages to notify the students about the rules and regulations for extensions. The informing email genre message regarding issues such as due dates to submit exam results produced enquiry genre messages to part-time lecturers requesting the examination results and the completed marksheet. A delivery genre message to external examiners that encloses proposed assignments or examination papers produced a discussion regarding about how to set up a good assignment or examination paper. These instances of functional intertextuality in the different types of email genres reflected how the employees of the educational institution linked past texts to future texts to accomplish their institutional tasks.

\subsection{Generic Intertextuality}

Generic intertextuality or "vertical intertextuality" (Johnstone, 2008) refers to the reoccurring forms in reoccurring rhetorical situations (Devitt, 1991). As such, this type of intertextuality "defines and serves the needs" (Devitt, 1991: p. 339) of the discourse community. As a discourse community, the employees of the private higher educational institution, subject of the study, respond to reoccurring rhetorical situations. These reoccurring rhetorical situations arises as the academic and institutional needs of the employees be inclined to reoccur.

Generic intertextuality occurred in the use of certain framing moves (AlAfnan, 2015a), on the one hand, and several content moves, on the other. In relation to the framing moves, email genre messages comprised six moves that are the "identifying topic", "salutation", "opening", "pre-closing", "closing", and "signature" moves. These framing moves collectively or selectively occur in business letters, memorandums and business fax genres (Chadessy, 1993; Flowerdew \& Wan, 2006; Louhiala-Salminen, 1999; Zhu, 2005). The occurrence of 
the "identifying topic" (reference), "salutation", "closing" and "signature" moves was an obligatory element, especially in the emails that were sent to a group of recipients, which is also the case in business letter genre (AlAfnan, 2016; Chin, 2011; Jalilifar \& Beitsayyah, 2011; Santos, 2002). The occurrence of these moves in the emails that intended to discuss and issue, request information or files and deliver documents, however, appeared to be optional, which is also the case in memo and fax genres (AlAfnan, 2016; Akar \& Louhiala-Salminen, 1999; Yates \& Orlikowski, 1992).

In relation to the content moves, however, the use of reoccurring forms in reoccurring rhetorical situations was recorded in the use of formulaic constructs in "referring to previous contact", "indicating enclosure", "responding to requests", "requesting confirming receipt", and "offering help if needed" communicative moves. In "referring to previous contact" move, the main informants used adverbial subordinates "with reference to" and compound prepositions "as per your email message" to refer to previous contacts. They intended to link the email message to a previous point of contact, which created "referential intertextuality" (Devitt, 1991) or "manifested intertextuality" (Fairclough, 1992). It seemed that this practice occurred in two types of email genres that are discussion and enquiry email genres (AlAfnan, 2015a), which also creates generic intertextuality (Devitt, 1991). As these two types of email genres occur in chains, the writers used the same formulaic forms to respond to the reoccurring situations by placing the genre in its communicative context.

This kind of "vertical intertextuality" was also recorded in the use of "please find attached" and "enclosed please find" formulaic constructs in "indicating enclosure" and "responding to requests" rhetorical moves in delivery and enquiry email genres (AlAfnan, 2015a). The act of sending files in delivery email genre was an "initiative". That is, the writer deliberately sent the file to the addressee as part of his/her organizational duties or responsibilities. In the "responding to request" move, however, the act of sending the files or the documents is a "reply". That is, the delivery of the files or documents in the "responding" move is a reaction to a "requesting" email. As the rhetorical need for delivering files and documents reoccurred in these two situations, which belong to two types of email genres, the main informants used the same rhetorical forms in carrying out the intended tasks.

Generic intertextuality was also recorded in "requesting confirming receipt" and "offering help if needed" moves in delivery and informing email genres. The use of the "requesting confirming receipt" move is an endorsing strategy that intended to validate that the sender carried out the action, and the recipient has received or is fully informed about the issue. Therefore, he/she is expected to act upon the given information. The main informants mainly used two formulaic expressions to "request confirming receipt" that are "kindly acknowledge receipt" and "appreciate confirming receipt". As the rhetorical need of confirming receipt reoccurred in delivery and informing email genres, which do not usually require a reply, the main informants used these rhetorical forms to solicit an ac- 
tion from the recipients. Similarly, the main informants mainly used two conditional formulaic constructs, "if you have any quires, please do not hesitate to contact me" and "should you have any quires, please call me", in "offering help if needed" move. The use of this move and the two constructs occurred in delivery and informing email genres to express the availability of the sender. As this rhetorical need reoccurred in two types of email genres, the main informants used the rhetorical moves to execute the same intention.

Overall, the occurrence of generic intertextuality in different types of email genre reflects the reoccurring rhetorical needs of the discourse community. As the main informants write a new text, they refer to their previous knowledge and experience of writing such texts in the discourse community, which, as a result, creates these reoccurring forms in the reoccurring situation (Devitt, 1991).

\section{Patterns of Interdiscursivity}

Interdiscursivity, according to Jianguo (2011), refers to "the mixing of diverse genres, discourses, or styles associated with institutional and social meanings in a single text" (p. 95). Unlike intertextuality, which examines the text-internal factors, interdiscursivity examines the text-external factors of genres. Even though genres are defined as "conventionalized discursive action" (Bhatia, 2004: p. 87), they are, however, developing (Berkenkotter \& Huckin, 1995) and dynamic (Bhatia, 2002). This could be noticed in appropriating the generic resources of certain genres when constructing another, which creates embedded, mixed or hybrid genres (Bhatia, 2002, 2004, 2008). This "genre mixing" occurs as the expert members of the discourse community exploit "private intentions" to achieve a number of complementary or even conflicting communicative purposes (Bhatia, 2002, 2004).

According to AlAfnan (2015a), email genre is an umbrella of four different types of genres. Discussion email genre is used to elaborate on issues and seek opinions. Requesting email genre is used to request and respond to requests. Delivery email genre is used to send files and informing email genre is used to notify a group of recipients of general interest issues. Overall, the four types of email genres were conventionalized and static, particularly, with respect to their communicative intentions and generic structure. However, a number of email genre messages invaded the generic integrity of other types of genres, which, as a result, produced hybrid or mixed genres. This appropriation of generic resources of a genre to create another was witnessed in three out of the four types of email genres and was carried out on the "lexico-grammatical, rhetorical and discoursal" levels (Bhatia, 2010 p. 87). Thus, interdiscursivity in email genres is produced through the mixing of two genres or two styles.

\subsection{Hybrid Genres: Genre Mixing}

Hybrid or mixed genres (Bhatia, 2012) in the email messages was created by the mixing of two types of email genres in a single email message. The writers appropriated the generic resources of a genre to create another. This practice was 
recorded in discussion and enquiry email genres. The members of the discourse community mainly appropriated the generic resources of a discussion email genre message to create a discussion-informing or a discussion-enquiry email genre message, and an enquiry genre message to create an enquiry-discussion email genre message, where the first communicative purpose was the main purpose of the message and the second purpose was a subordinate purpose. The employees mixed complementary and conflicting communicative purposes in one email message.

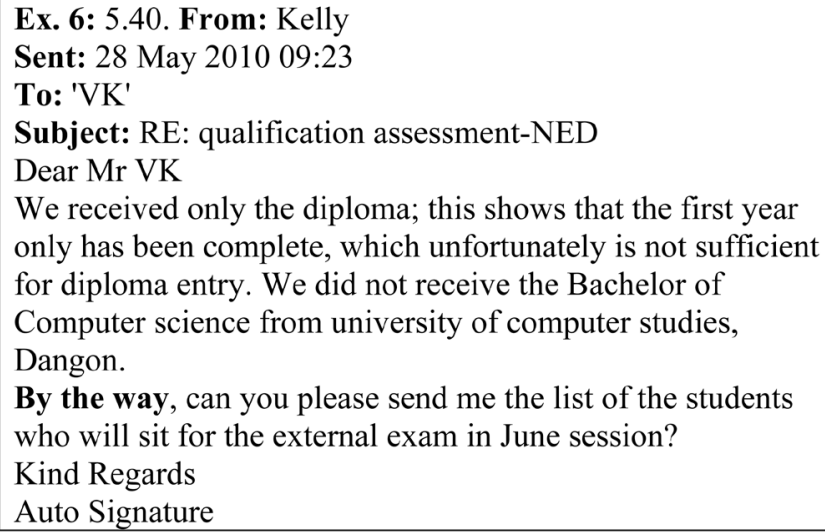

In example (6) above, the writer mixed two main content moves that are "discussing issues" and "requesting" moves in a single email message. These two moves were identified as two obligatory or genre-defining content moves in two types email genres that are discussion and enquiry email genres (AlAfnan, 2015a). As the content of the email shows, the communicators discussed the case of a student who has a degree from another institution and applied to NED wishing to receive exemptions. This was carried out in a number of declarative mood sentences that intended to present information (Biber, 1995). However, towards the end of the email, the writer requested the list of students who will sit for the exam, using the modal initial indirect request "can you please...". Requesting was identified as a type of email genre (AlAfnan, 2015a). It appeared that the writers basically request information or documents in separate emails. In addition, the requesting move or communicative purpose seems to be in conflict with the original communicative purpose of the email, which discusses the possibilities of granting exemptions to a student. The writer of the email seems aware of changing the topic and the communicative intention of the email as he used "by the way" in front of the requesting move to indicate that the following statement or question is unrelated to what had been discussed earlier.

The main intention of mixing these two conflicting communicative purposes in a single email is the writer's intention to save time and effort. As the exchange of ideas in the discussion email genre chain was carried out over a period of time in a number of out-going and in-coming emails (AlAfnan, 2015a), another organizational need arises that also involves the academic director, who is involved in the discussion chain. As a matter of convenience, the writer chose to appro- 
priate the generic resources of the discussion email genre chain to include the enquiry move.

In addition to mixing two conflicting communicative purposes in a single email genre message, staff members also mixed two complementary communicative purposes in a single discussion email genre message. This was the result of mixing a discussion and informing email genres. In this case, unlike the identification of the conflicting communicative purposes that was acknowledged by using different grammatical moods alone, the identification of the two complementary communicative purposes was recognized by the function of the segments, on the one hand, and the variation in the lexico-grammatical features used in the correspondence, on the other.

In example (7) below, the head of studies wrote an email to a student as they were discussing extensions on submitting an assignment. This argument was carried out in a number of emails that involved administrative staff and lecturers. As the discussion reached the head of studies, she wrote this email that included a number of passages. In these excerpts, it seems that the writer used two different tones to achieve two different communicative purposes. In the first passage, the writer used a personal tone to further discuss the issue of giving extensions. In this passage, the writer was personally involved in the email as she mainly used active voice clauses and first and second person pronouns (Biber, 1995). The style of writing was more of spoken than written as she hedged her opinion using "I guess", which is an informal strategy that is used in oral communication (Biber, 1995), and used the private factual verb "think", which signify her state of mind (Quirk et al., 1985).

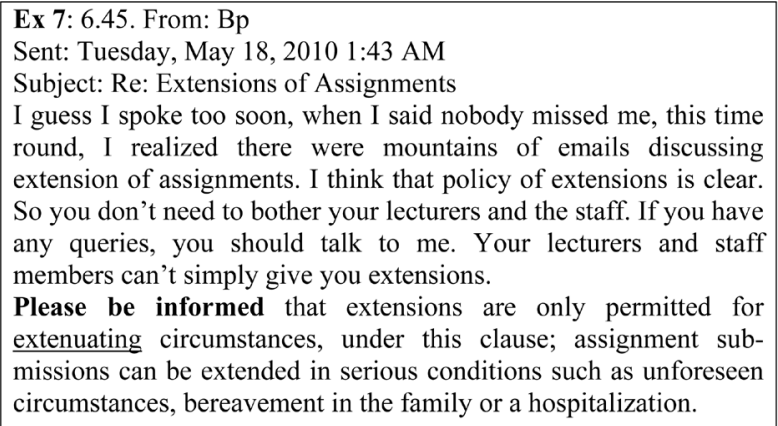

In the second passage, the writer moved to a second communicative purpose, which is formally informing the student about the rules and regulations of granting extensions in the institution. This change in the communicative intention also carried a change in the use of the lexico-grammatical features. The style in the second passage changed from a personal writing-like-speaking into a formal and informative style. This is observed in the use of agentless passive voice clauses that demote any animate involvement and promote inanimate referents that are the "extensions" and "assignment submissions". The second passage, in addition, did not include any hedges, private verbs, or personal pronouns, which reflect informational writing (Biber, 1988). To attract the attention of the stu- 
dent, the writers used the signposting device using a suasive verb, "please be informed", which lessens or limits the role of the agent in the writing. The linguistic features of the first passage were conventional in discussion email genre as the writer and the recipient were directly involved in the communication. The informative style in the second passage, however, is conventional in informing email genre messages. Appropriating the genic resources of discussion and informing email genres to create the hybrid "discussion-informing" genre in this email message seems driven by a private intention (Bhatia, 2008).

Apparently, the main intention of mixing the discussion and the informing email genre messages in this email is writer's private intention to "put-an-end" for the on-going discussion. The active style in discussion genre messages encouraged the student to negotiate the issue. Even though the head of studies explained that she could not grant the student an extension, the student continued his negotiating style in a number of email messages. Therefore, the head of studies chose to mix the discussion and the informing communicative purposes to firmly conclude the on-going argument regarding the respected issue.

Mixed or hybrid genres occurred in 30 email messages that were mostly parts of threads or chains discussing an issue. Obviously, the prolonged exchange of ideas in a number of emails over a period of time encouraged the writers to appropriate the generic resources of a genre to create another. It appears that hybridization occurred as a product of convenience, on the one hand, and the writers' aspiration to save time and effort, on the other.

\subsection{Hybrid Styles: Written vs. Spoken Including Non-Verbal}

The email messages included features of written and spoken styles. In general, the writers of the four types of email genres regarded their email communications as written discourse. This was reflected in the structural patterns of the emails as they included proper "subject", "salutation", "closing", and "signature" moves. This was also apparent in the content of the emails, as the writers used structured declarative, imperative and interrogative sentences to present information, direct the addressee and enquire or request information. They also used passive voice constructs (Biber, 1988), public verbs, suasive verbs (Quirk et al., 1985) and professional terminology (Chin, 2011).

Ex 8: 3.5. From: $\underline{\text { LG }}$
To: BP
Cc: MI
Sent: Monday, April 26, 2010 6:42 PM
Subject: New Institution Officer
Dear BP
You are informed that from today CA H will be your new
Institution Officer. She will now be your first point of
contact for all Credit Transfer, Matriculation, Uploading of
transfers and Certificates and Transcripts.
Best Wishes
LG
Position
Name of organization
Address, contact details


As example (8) above shows, the writer used a clear "subject" move that reflects the content of the email, a proper "salutation" that is preceded by a formal salutation-marker, proper "closing" and proper "signature" move that included the name, institutional position, name of institution, and the contact details of the sender. In the content of the email, the writer used the passive voice formulaic construct "you are informed that" to demote the agent, and the suasive verb "informed" to report or establish the purpose of the email message. The sentences are long, clear and direct, which makes it easier for the recipient to comprehend the message. In addition, the writer used a number of professional terminologies (i.e., Credit Transfer, Matriculation, Uploading of transfers) to mark the referents (Chin, 2011). Thus, this informing email genre message is regarded as a formal email message.

The employees mainly used these formal features in their email communications with governmental authorities, external partners, students and internal emails that were sent to a number of recipients at the same time. These features also occurred in the internally sent emails that intended to enforce a rule, remind the employees about an institutional issue, or formally notify an employee or a lecturer about their duties. This style of writing was used mainly as an imposing method, convincing method, and giving information or instructions method. The emails that included formal written features were mainly direct and passive in relationship to the involvement between the addresser and the addressee.

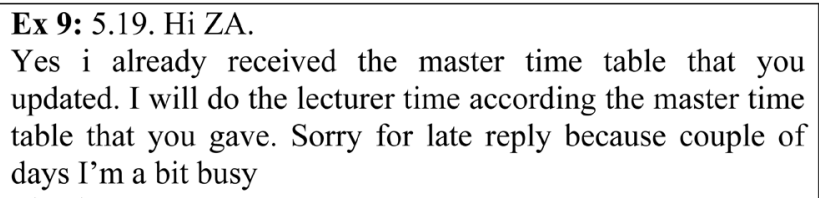

In contrast to the features used in example (8), the writer of example (9) above was greatly involved in the email message. He used the first person pronoun " $p$ " a number of times, which reflects great involvement and personal writing (Biber 1995). Additionally, the writer used a number of spoken features as in the use of " $H i$ " as a salutation marker, "thanks" as a closing marker, and the use of the contraction " $I$ 'm". In addition to these features, the writer apparently did not edit or proofread the email which can be noticed in the typo errors as in " $r$ cived", the lower case used for the first person pronoun " $P$ ", and a number of missing comas and periods. Additionally, the word order in the last sentence seems "sloppy".

Examining the corpus of email messages reveals that spoken features mainly occurred in the internally exchanged email messages depending on power relations and social distance between the employees. Mr. VK, the writer of example (9), is the superior of Ms. ZA, the recipient. They are close colleagues. Thus, this email was written by a superior to a close colleague subordinate to respond to an internal email enquiry. The close social distance between the employees influ- 
enced the framing formality, on the one hand, and the formality of the content, on the other. This is also a result of writers' reluctance to edit or proofread these internally exchanged emails before sending them. In addition to the hybrid discourse, these internally sent emails included some typographical errors, which may negatively affect the professional image of the writer.

In addition to relational factors, the frequent exchange of emails regarding an issue also influenced the type of discourse used in the emails. The occurrence of spoken features mainly took place in the embedded emails (Gimenez, 2005) that were discussing an issue over a number of email messages. As the writers discussed an issue in a number of out-going and in-coming emails, the formality of the emails gradually declined. The writers mainly used formal written salutation and closing markers in the first email and the first reply; however, as the discussion grew longer, the writers used a variety of formal, informal, conversational or even no salutation or closing markers. This practice also influenced the formality of the content, which can be noticed in the use of minimizations, ellipsis, substitution and contractions became a practice in these emails.

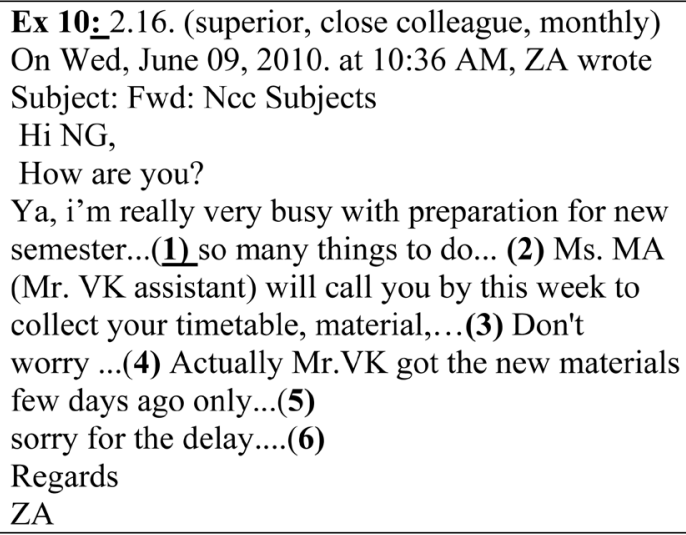

In regard to the use of ellipsis, the writers used two different methods that are the dots technique (...), in which the writer hinted at the omitted words or clauses using a number of dots, or naturally as in spoken discourse. The usage of the dots technique reflects an intentional ellipsis (omission) as a result of writers' reluctance to detail the omitted part, whereas the usage of the natural ellipsis occurred as a result of writing-like-speaking style. As example (10) above shows, the writer, who is the head of students' counselling unit, used six instances of ellipsis in a single email, assuming that the recipient of the email is capable of working out the omitted words and clauses. The occurrence of these ellipses markers reflects an informal writing-like-speaking style. In addition, the writer used an informal salutation " $h i$ ", which is a practice among close colleagues, a conversational opening "how are you?", and a contraction "I'm". As mentioned earlier, ellipsis and ellipses markers only occurred in the internally exchanged discussion and enquiry email genre messages, which reflected writers' awareness of the informal and spoken nature of this "syntactic process" (Kennedy, 1998: p. 90). 
Ex 11: 1.31. I will do the correct one later

Ex12: 7.52. Except the ones sent by Mr. DS

Ex 13: 6.31. We should make use of the same.

Ex 14: 7.53. If she does, will she be able to forward to me around fifty.

Ex 15: 3.13. If $\underline{\text { so, }}$, see you there then.

Similarly, the main informants also used substitution in their internally exchanged email messages. The informants used one "one", "ones" and "the same" to substitute a noun, "does" to replace a verb and "so" to replace a clause. The majority of the substitutions in the emails were used to replace a noun. The usage of "one" and "ones" were the most common substitution devices, as they were used to replace singular and plural nouns, as in example (11) and example (12). As the usage of ellipsis, the writers used substitution to skip the repetition of the same noun, verb, or clause a number of times and to extend the cohesion or the textual domain of a sentence to another sentence, which means that all substitutions refer to anaphoric items. In example (11), the writer used "one" to replace "themarksheet" mentioned in previous email, exophoric referencing. The writer submitted the marksheet previously; however, the recipient found a number of mistakes, which needed to be corrected. In response, the writer of example (11) below did not use the word "marksheet" however, replace it with "one". In example (15), however, the writer replaced the whole if-clause using "so". Returning to the email shows that "so" refers to the possible answer of question presented earlier in the email, endophoric referencing. The sender asked "are you going to attend the workshop or not?" so to avoid writing "if you are coming", and to extend the semantic realm of the sentence, the writer used "so" to replace the whole if-clause. Substitution occurred in 26 internally exchanged email messages, which reflects employees' awareness of the informal and spoken nature of this feature.

In addition to these written and spoken discourse features, the writers of the emails also made use of non-verbal cues or paralinguistic features (Sully \& Dallas, 2005). The corpus included twenty instances of emoticons that basically occurred in the chain type messages. The emoticons were either manually typed as in (:)) or chosen from the provided list of emoticons in the formatting of the emails as in (-)). As example (16) below shows, the writer of the email, who is a part-time lecturer, used three manually typed emoticons. As the email included an enquiry, which is a face-threatening-act (FTA) (Brown \& Levinson, 1987), the sender wanted to minimize the imposition by using friendly facial expressions. The first emoticon, which is a smiling face (:)), was used after an opening sentence, which shows sympathy to the addressee. The writer wanted to show understanding that the addressee is "busy", which is a positive politeness strategy (Brown \& Levinson, 1987). 
Ex 16: 2.14 .

Hi ZA,

Hows things? Pretty sure that you have your hands full:)

Any news on when I shall come over for material collection? ;) With less than 3 weeks for class commencements, I am getting worried that I might have difficulties if the materials are going to be delivered late: $\mathbf{D}$

Just give me a quick call on either my hp or house (xxxxxxxxx) yea!

Thank you.

$-\mathrm{NZG}$

The second emoticon, which is a wink (;)), was used after the FTA, "any news on when...". The wink here intends to minimize the imposition implying that this is a friendly reminder, especially that there are only three weeks left before the new semester commences. However, wishing that the recipient did not take the previous sentence as a complaint or assertion, she used the third emoticon, which is an open-mouth smile (:D), to minimize the imposition. The emoticons were used as a supportive technique to add lively facial expressions to weaken the impact of the FTA, especially among close colleagues in the internally exchanged emails.

\section{Conclusions}

The construction of email genres included instances of several types of intertextuality, which reflects interrelationships within and across texts (Bhatia, 2010a). Referential intertextuality, for example, occurred in the four types of email genres, however, for different purposes. In discussion and inquiry email genres, this kind of intertextuality was used mainly to refer to a previous point of contact between the communicators. This mainly occurred in "referring to previous contact" move, in which email writers referred to previous emails, letters, faxes, conversations, and telephone calls. This was carried mainly out using compound prepositions "as per" and adverbial subordinates "with reference to". Referential intertextuality in informing email genre, however, mainly occurred in the main content move to tie the given information to the rules and regulations in general or a given policy in particular. This was carried out using conjuncts as in "in accordance with". This strategy was also used in discussion email genre to put an end for a lengthy discussion. In delivery genre, however, referential intertextuality occurred as a strategy to denote an attached document. This referential or "horizontal" intertextuality was marked mainly using formulaic expressions such as "please find attached" or "enclosed please find".

Functional intertextuality was also common in the four types of email genres. This was recorded in two strategies that are the influence of previous texts on a new text by creating the need of the new text and the use of the "cut-paste" technique. The former strategy was recorded explicitly in discussion and enquiry email genres and was marked by the "RE" and "FW" initials in front of the 
"identifying topic" move of the "replied" and "forwarded" email messages, and implicitly in the four types of email genres. The use of the explicit functional intertextuality mainly created chains of in-coming and out-going email messages that debated an issue, brought the issue to the attention of a director or head of a department or respond to a request. The implicit functional intertextuality, however, was not marked by a sign. It took complex forms that reflected the sequence of texts in the educational institution. As the corpus was collected over 45 days of day-in-day-out communications, examining the sequence of texts revealed that a discussion chain regarding extensions to submit assignments might result into an informing email genre message to all students "informing" them about the rules and regulations of extensions. Similarly, a delivery email genre message may result in an enquiry in another email message, an informing email genre message may create a chain of discussion email genre messages, and an enquiry genre message may result into a delivery or an informing email genre message. The "cut-paste" strategy, however, was used mainly in informing email genre as the writers used their "professional knowledge" (Devitt, 1991) in the field to carry out certain practices. This was reflected in "pasting" whole segments of texts, mainly from the rules and regulations, into the body of the informing email genre messages to state the obligation of certain practice or procedure.

Generic intertextuality, however, occurred as a result of using reoccurring forms in reoccurring rhetorical situations. This was recorded in the use of the framing moves, which are intrinsic moves in business communications genres, and a number of content moves. The use of reoccurring forms was recorded in the use of adverbial coordinates "with reference with" and compound prepositions "as per our conversation" in "referring to previous contact" move in discussion and enquiry email genres to link the email to its communicative context. It was also recorded in the use of "please find attached" and "enclosed please find" formulaic constructs in the delivery and enquiry email genres to divert the attention of the recipient to the attached files. The use of reoccurring forms was also recorded in "requesting confirming receipt", "kindly acknowledge receipt", and "offering help if needed", "if you have any quires please do not hesitate to contact me", moves in delivery and informing email genres. Similarly, the formulaic constructs were also used in the informing email genre as the writers used the passive voice constructs "please be informed", "you are required" and "you are informed" to prepare the addressee for the following information. This practice reflects the reoccurring rhetorical needs of the discourse community, on the one hand, and referring to previous knowledge of carrying out tasks within the community, on the other (Devitt, 1991).

Primarily, the four types of email genres maintained their generic integrity; however, there were instances of appropriating the generic resources of genre to create another (Bhatia, 2004). There were also instances of hybrid discourse. Appropriating the generic resources of a genre to create another was a result of communicating private intentions in the socially recognized communicative 
purposes (Bhatia, 2010a). This occurred as a number of the emails included two complementary or conflicting communicative intentions. This practice mainly occurred in discussion and enquiry email genres. The writers mainly mixed a discussion with an enquiry email genre messages, which created a "discussion-enquiry" email genre, or a discussion and informing email genre messages, which created a "discussion-informing" email genre message. These "hybrid genres" or imbedded genres" occurred in 30 email messages, which is 8 percent of the corpus of email messages. This reflects that 92 percent of the emails maintained their generic integrity. The main purpose of creating the "hybrid genres" (Bhatia, 2012) is the writers' intentions to save time and effort, especially in the chain-type messages that were exchanged in a number of email messages over a period of time.

Hybrid discourse also occurred in discussion and enquiry email genres that were exchanged internally or sent to students. The informants in these emails mixed written and spoken discourses including non-verbal cues. The writers of the internally exchanged discussion and enquiry email genre messages mainly used formal written features including salutation and closing markers in the first a few email message of the chain. As the chains grew longer, the formality of these emails declined as they included spoken features such as ellipses, substitution and contractions. Some emails also included minimizations and non-verbal cues to add lively facial expressions to the correspondence. The occurrence of these features was mainly a result of the writers' intention to minimize the imposition by using emoticons, extending the textual domain of a sentence to another by using substitution, writers' reluctance to elaborate on certain issues by using dots ellipsis, and finally writing-like-speaking style, which was reflected in the use of contractions and minimizations. As these features mainly occurred in the internally exchanged discussion and enquiry email genre messages only, this reflects the influence of relating factors on language use, especially that these features occurred in the emails that were sent to close colleagues. These features, however, did not occur in the externally sent discussion and enquiry email genre messages, which reflects writers' awareness of the informal nature of these features. The occurrence of these features was not common in delivery email genre and did not occur in informing email genre, which mainly included "written discourse" features. The occurrence of "mixed discourse" in the emails that were sent to students, however, mainly intended to connect with the students on the personal level.

\section{References}

Afnan, A., \& Mohammad, M. A. (2014a). Language Use as an Institutional Practice: An Investigation into the Genre of Workplace Emails in an Educational Institution. Doctoral Dissertation, Sintok: Universiti Utara Malaysia.

Akar, D., \& Louhiala-Salminen, L. (1999). Towards a New Genre: A Comparative Study of Business Faxes. In F. Bargiela-Chiappini, \& C. Nickerson (Eds.), Writing Business: Genres, Media and Discourses (pp. 227-254). London: Longman.

AlAfnan, M. A. (2014b). Politeness in Business Writing: The Effects of Ethnicity and Re- 
lating Factors on Email Communication. Journal of Modern Linguistics, 4, 275-289. https://doi.org/10.4236/ojml.2014.42022

AlAfnan, M. A. (2014c). Interethnic Workplace Email Communication: An Investigation into Politeness Strategies. In Proceedings of the 2014 International Conference on Public Management and Education Research.

AlAfnan, M. A. (2015a). Language Use in Computer-Mediated Communication: An Investigation into the Genre of Workplace Emails. International Journal of Education and Literacy Studies, 3, 1-11.

AlAfnan, M. A. (2015b). Asynchronous Communication: Investigating the Influences of Relational Rlements and Background on the Framing Structure of Emails. Advances in Language and Literary Studies, 6, 44-50.

AlAfnan, M. A. (2015c). Analyzing the Rhetorical, Typographical and Paralinguistic Features of Electronic Mails in the Workplace. International Journal of Applied Linguistics \& English Literature, 4, 77-85.

AlAfnan, M. A. (2016). Textography: A Multi-Dimensional Applied Genre Analysis of Business Writing in an Educational Institute. Journal of Applied Linguistics and Language Research, 3, 264-294.

Bakhtin, M. (1981). Discourse in the Novel (M. Holquist, \& C. Emerson, Trans.). In M. Holquist (Ed.), The Dialogic Imagination (pp. 259-422). Austin: University of Texas Press.

Berkenkotter, C., \& Huckin, T. N. (1995). Genre Knowledge in Disciplinary Communication: Cognition/Culture/Power. Hillsdale, NJ: Erlbaum.

Bhatia, V. K. (2002). Applied Genre Analysis: Analytical Advances and Pedagogical Procedures. In A. M. Johns (Ed.), Genre in the Classroom: Multiple Perspectives (pp. 279-283). Mahwah, NJ: Erlbaum.

Bhatia, V. K. (2008). Genre Analysis, ESP and Professional Practice. English for Specific Purposes, 27, 161-174.

https://www.researchgate.net/publication/223036568_Genre_analysis_ESP_and_profes sional_practice https://doi.org/10.1016/j.esp.2007.07.005

Bhatia, V. K. (2010a). Interdiscursivity in Professional Communication. Discourse and Communication, 21, 32-50. https://doi.org/10.1177/1750481309351208

Bhatia, V. K. (2010b). Accessibility of Discoursal Data in Critical Genre Analysis: International Commercial Arbitration Practice. Linguagem em (Dis)curso, 10, 465-483. http://wac.colostate.edu/siget/lemd/100302.pdf

Bhatia, V. K. (2012). Critical Reflections on Genre Analysis. Ibérica, 24, 17-28. http://www.aelfe.org/documents/03_24_Bhatia.pdf

Bhatia. V. K. (2004). Worlds of Written Discourse: A Genre-Based View. London: Continuum International.

Biber, D. (1988). Variation across Speech and Writing. New York, NY: Cambridge University Press. https://doi.org/10.1017/CBO9780511621024

Biber, D. (1995). Dimensions of Register Variation: A Cross-Linguistic Comparison. Cambridge: Cambridge University Press. https://doi.org/10.1017/CBO9780511519871

Brown, P., \& Levinson, S. (1987). Politeness: Some Universals in Language Usage. Cambridge: Cambridge University Press.

Chin, I. C. (2011). A Critical Genre Study of Written Professional Discourse. Doctoral Thesis, Hong Kong: Hong Kong Polytechnic University. 
http://repository.lib.polyu.edu.hk

Devitt, A. (1991). Intertextuality in Tax Accounting: Generic, Referential, and Functional. In C. Bazerman, \& J. Paradis (Eds.), Textual Dynamics of the Professions: Historical and Contemporary Studies of Writing in Professional Communities (pp. 336-357). Madison: University of Wisconsin Press.

Fairclough, N. (1992). Discourse and Social Change. Cambridge: Polity Press.

Fairclough, N. (1993). Critical Discourse Analysis and the Marketization of Public Discourse: The Universities. Discourse and Society, 4, 133-168. https://doi.org/10.1177/0957926593004002002

Fairclough, N. (2003). Analyzing Discourse: Textual Analysis for Social Research. London: Routledge.

Flowerdew, L., \& Wan, A. (2006). Genre Analysis of Tax Computation Letters: How and Why Tax Accountant Write the Way They Do. English for Specific Purposes, 25, 133-135. https://doi.org/10.1016/j.esp.2005.03.005

Fowler, R., Hodge, B., Kress, G., \& Trew, T. (1979). Language and Control. London: Routledge and Kegan Paul.

Gimenez, J. C. (2005). Unpacking Business Emails: Message Embeddedness in International Business Email Communication. In P. Gillaerts, \& M. Gotti (Eds.), Genre Variation in Business Letters. Linguistic Insights: Studies in Language and Communication (Vol. 24, pp. 235-255). Bern: Peter Lang.

Halliday, M. A. K. (1985). Systemic Background. In J. D. Benson, \& W. S. Greaves (Eds.), Systemic Perspectives on Discourse (Vol. 1). Norwood, NJ: Ablex.

Hasan, R. (1977). Text in the Systemic-Functional Model: Current Trends in Text Linguistics. Berlin: Walter de Gruyter.

Jalilifar, A., \&Beitsayyah, L. (2011). Genre Analysis of Enquiry Letters across Cultures: Perspectives on Rhetorical Structures. Studies in Linguistics, 37, 309-333. http://www.concentric-linguistics.url.tw/upload/articlesfs271402111221127791.pdf

Jianguo, W. E. (2011). Understanding Interdiscursivity: A Pragmatic Model. Journal of Cambridge Studies, 6, 95-115.

http://www.journal.acs-cam.org.uk/data/archive/2011/201123-article8.pdf

Johnstone, B. (2008). Discourse Analysis (2nd ed.). Malden, MA: Blackwell Publishing.

Jones, L. A., \& Freeman, T. E. (2003). Imitation, Copying and the Use of Modals: Report Writing in an Introductory Physics Course Writing. IEEE Transactions on Professional Communication, 46, 168-184.

https://doi.org/10.1109/TPC.2003.816790

Kennedy, G. (1998). An Introduction to Corpus Linguistics: Studies in Language and Linguistics. London: Longman.

Kress, G., \& Hodge, R. (1979). Language as Ideology. London: Routledge \& Kegan Paul.

Kristeva, J. (1980). Word, Dialogue and Novel. In L. S. Roudiez (Ed.), Desire in Language: A Semiotic Approach to Literature and Art (pp. 64-91). New York, NY: Colombia University Press.

Kristeva, J. (1986). The Kristeva Reader. New York, NY: Columbia University Press.

Louhiala-Salminen, L. (1999). Was There Life before Them? Fax and Email in Business Communication. The Journal of Language for International Business, 10, 24-38. http://www.hse.fi/FI/publications/publication.htm

Musson, G., \& Cohen, L. (1996). The Enterprise Discourse: An Empirical Analysis of Its Effects. In The Conference of Communication and Culture: China and the World Entering the 21st Century. 
Orlikowski, W., \& Yates, J. (1994). Genre Repertoire: The Structuring of Communicative Practices in Organizations. Administrative Science Quarterly, 39, 541-574. https://doi.org/10.2307/2393771

Pecheux, M. (1982). Language, Semantics and Ideology. London: MacMillan. https://doi.org/10.1007/978-1-349-06811-1

Santos, V. B. M. P. (2002). Genre Analysis of Business Letters of Negotiation. English for Specific Purposes, 21, 167-199.

http://www2.feu.ac.th/admin/pr/newscontrol/atts/D20120524222001.pdf https://doi.org/10.1016/S0889-4906(00)00028-4

Sarangi, S. (2000). Activity Types, Discourse Types and Interactional Hybridity: The Case of Genetic Counseling. In S. Sarangi, \& M. Coulthard (Eds.), Discourse and Social Life (pp. 1-27). London: Pearson Education Limited.

Simpson, P. (1993). Language, Ideology and Point of View. London: Routledge. https://doi.org/10.4324/9780203312612

Sully, P., \& Dallas, J. (2005). Essential Communication Skills for Nursing. Edinburgh: Elsevier Mosby.

Swales, J. M. (1990). Genre Analysis. English in Academic and Research Settings. Cambridge: Cambridge University Press.

Van Dijk, T. A. (1993). Principles of Critical Discourse Analysis. Discourse and Society, 4, 249-283. https://doi.org/10.1177/0957926593004002006

Wodak, R. (2006). Critical Linguistics and Critical Discourse Analysis. In J. O. Ostman, \& J. Verschueren (Eds), Handbook of Pragmatics (pp. 1-24). Amsterdam: John Benjamins. https://doi.org/10.1075/hop.10.cri1

Yates, J., \& Orlikowski, W. J. (1992). Genres of Organizational Communication: A Structurational Approach to Studying Communication and Media. Academy of Management Review, 17, 299-326.

Zhu, Y. (2005). Effective Communication in Business Chinese Fax Writing. In F. Bargiela-Chiappini, \& M. Gotti (Eds.), Asian Business Discourse (pp. 103-120). Bern: Peter Lang. 
Submit or recommend next manuscript to SCIRP and we will provide best service for you:

Accepting pre-submission inquiries through Email, Facebook, LinkedIn, Twitter, etc. A wide selection of journals (inclusive of 9 subjects, more than 200 journals)

Providing 24-hour high-quality service

User-friendly online submission system

Fair and swift peer-review system

Efficient typesetting and proofreading procedure

Display of the result of downloads and visits, as well as the number of cited articles Maximum dissemination of your research work

Submit your manuscript at: http://papersubmission.scirp.org/

Or contact ajc@scirp.org 